\title{
"Nossa Luta é Transversal": Ocupação Tereza de Benguela e a Luta das Mulheres do MTST
}

\section{"Our Struggle is Transversal": Occupation Tereza de Benguela and MTST Women's Struggle}

\section{Carolina Guida Cardoso do Carmo*}

Resumo: Esse artigo se propõe a refletir sobre a correlação da luta das mulheres dentro dos movimentos de moradia, tendo, como campo de observação, a Ocupação Tereza de Benguela, localizada na zona leste de São Paulo e vinculada ao Movimento dos Trabalhadores sem Teto (MTST), desenvolvido no período de 2019. Utilizando, como embasamento para o artigo, a fala de liderança da ocupação e entrevista com pesquisadora do movimento, tem-se uma discussão que intersecciona a luta da ocupação com especificidades vivenciadas pelas mulheres e que observa pontos comuns de experiências, proporcionando uma significativa forma de construir uma luta feminina e popular.

Palavras-chave: Movimento Social; Mulheres; Feminismo

\begin{abstract}
This article aims to reflect on the correlation of women's struggle within housing movements, using the Tereza de Benguela Occupation as an observation field, located on the east side of São Paulo and linked to the Homeless Workers Movement (MTST), developed in 2019. Using as the basis for the article the speech of leadership of the occupation, as well as an interview with a researcher from the movement, we resulted in a discussion that intersects the struggle of the occupation with specificities experienced by women and that observes common points of experiences, providing a significant way of building a feminine and popular struggle.
\end{abstract}

Keywords: Social movement; Women; Feminism

* Doutoranda e Mestra pelo Programa de Pós-Graduação em Arquitetura, Tecnologia e Cidade da Universidade Estadual de Campinas.Especialista em Cidade, Planejamento Urbano e Participação Popular pela Universidade Federal de São Paulo. Arquiteta Urbanista pelo Centro Universitário Nossa Senhora do Patrocínio. E.mail: carolinagcdocarmo@gmail.com. 


\section{Introdução}

Nos últimos anos, observamos um interesse por pesquisas que busquem analisar, em diversos campos temáticos da ciência, a intersecção entre gênero, raça e classe, de maneira mais intensa e visível, dialogando com as crescentes transformações na compreensão de sociedade e aspectos de sociabilização que apresentam cada vez mais seus imbricamentos. O artigo apresentado nasce, também, do interesse científico em analisar esses conceitos de maneira justaposta, utilizando experiências empíricas de um campo específico de trabalho.

Resultado de um processo de pesquisa desenvolvido em 2019, este artigo tem como objetivo identificar aspectos práticos das experiências das mulheres na Ocupação Tereza de Benguela, vinculada ao Movimento dos Trabalhadores Sem Teto (MTST) e que nasceu em 2017, levando em consideração as intersecções entre gênero, raça e classe. A ocupação em questão está localizada na COHAB José Bonifácio, na região de Itaquera, na Zona Leste do município de São Paulo.

Para alcançarmos o objetivo proposto, trabalhamos com a lógica da metodologia dedutiva, utilizando-se tanto de pesquisa de campo qualitativa quanto de pesquisa teórica, sendo que o processo de pesquisa partiu das experiências empíricas do trabalho de campo para ser complementado, posteriormente, pela fundamentação teórica. Na etapa de campo, utilizamos, como principal elemento norteador da discussão, informações obtidas no depoimento dado por Claudia Garcez ${ }^{1}$, coordenadora estadual do MTST e coordenadora da ocupação Tereza de Benguela. Também foi realizada entrevista com a antropóloga Alana Moraes que, mesmo não sendo uma representação do movimento social de maneira direta, por não estar inserida no mesmo como moradora ou liderança, atuou junto ao MTST por alguns anos como pesquisadora (vinculada ao programa de Antropologia Social da Universidade Federal do Rio de Janeiro) e, portanto, apresenta relevantes contribuições e percepções sobre as mulheres dentro do movimento. As entrevistadas serão identificadas ao longo do trabalho como Claudia e Alana, respectivamente.

A partir de suas falas, pudemos nos ater a quatro pontos que se sobressaíram em suas narrativas e que, por consequência, conformaram a estrutura narrativa desse trabalho, sendo esses: i) a questão da interseccionalidade entre gênero e raça dentro da ocupação; ii) a violência contra a mulher; iii) a busca das participantes pela independência financeira; iv) a discussão sobre a categoria de feminismo popular.

Para a etapa teórica, foi estabelecida uma revisão de literatura relacionada aos conceitos-chave e temáticas que apareceram com maior ênfase na pesquisa de campo e, posteriormente, foram desenvolvidos os procedimentos necessários para compreensão dos principais aspectos desses trabalhos, como resumos e fichamentos, sendo possível alcançar, de maneira dialógica entre teoria e prática, o objetivo proposto.

\section{Movimentos Sociais e a Presença das Mulheres}

Para iniciarmos qualquer discussão sobre a pauta da mobilização popular e sua busca, seja por representatividade, atuação política e/ou poder de atuação no território, é importante

\footnotetext{
${ }^{1}$ Todas as informações nesse trabalho referenciadas como de Claudia Garcez, assim como os títulos e subtítulos grafados entre aspas, são informações adquiridas em palestra proferida pela mesma no seminário "Cidade, Gênero e Interseccionalidade", realizado pelo LabCidade (FAU/USP) em parceria com o Centro de Pesquisa e Formação do SESC, em janeiro de 2019. 0 depoimento completo está disponível através do podcast "PELA CIDADE \#especial Cidade, Gênero e Interseccionalidade", organizado pelos pesquisadores do LabCidade. Podcast disponível em: http://www.labcidade.fau.usp.br/pela-cidadeespecial-cidade-genero-e-interseccionalidade-11-claudia-garcez/
} 
retomar os processos de formação dos movimentos sociais enquanto ferramenta de luta em um contexto histórico, assim como suas motivações. De maneira geral, os movimentos sempre existiram e sempre existirão, pois representam forças organizadas em busca de experimentação social que é recriada diariamente a partir das adversidades das situações enfrentadas, resultando em inovações socioculturais (GOHN, 2011, p. 336). De acordo com a autora, os movimentos que "constroem ações coletivas que agem como resistência à exclusão e lutam pela inclusão social [...] desenvolvem o chamado empowerment de atores da sociedade civil."

O que os movimentos sociais são, e tem sido, está na descoberta que fazem de si mesmos como atores políticos, ou seja, na ideia e no exercício de uma participação equivalente, diferenciada e coletiva na condução dos assuntos públicos que lhes dizem respeito - por mais localizados que sejam. A sua importância não está no localismo e no comunitarismo de sua mobilização coletiva, mas no alcance que há, em cada uma destas mobilizações e ações, em sua enunciação como sujeitos coletivos de direitos. (PAOLI, 1991, p. 121)

Essa forma de interação social e acesso às diversas esferas de serviços e instituições é um trabalho que não pode ser ignorado na busca por um contínuo entendimento sobre as mudanças e reais características de uma cidade. Quando dizemos reais, entendemos como todo um cenário urbano amplo e diversificado, incluindo os setores marginalizados, junto com suas práticas culturais e sociais, que nem sempre são tidos como uma parcela formal e, portanto, evidentes aos olhos das práticas de planejamento (CARMO, 2019).

De acordo com Gohn (2011), os movimentos sociais populares latinos, os quais contribuíram decisivamente para a conquista de vários direitos sociais posteriores, como a Constituição Federal Brasileira de 1988, tiveram maior visibilidade a partir das décadas de 1970 e 1980 por se posicionarem contra os regimes militares, período em que houve uma tentativa de silenciamento e diminuição da participação popular nas discussões e representações sociais. Essas articulações se fortaleceram a partir de diversas pautas, como a falta de políticas públicas para equalizar as desigualdades urbanas, sendo que a temática da moradia, não só enquanto edificação mas também enquanto localização urbana (HELENE, 2019), permeou diversos desses grupos.

Paoli (1990) afirma que a gênese da luta dos movimentos sociais na América Latina é normalmente ligada às experiências de repressão e privatização da vida social, originando lutas contra a exclusão e tendo mulheres como protagonistas de algumas delas. A participação das mulheres, entretanto, foi lida como a extensão de seus tradicionais papeis femininos, conferindo à luta uma abrangência que não se aplicava na participação institucionalizada na esfera política e social. Essa atuação histórica institucionalizada está baseada na divisão sexual do trabalho, conceito adaptado historicamente a cada sociedade, mas que, prioritariamente, designou os espaços da esfera produtiva aos homens, reforçando a atuação dos mesmos junto às funções de forte valor social agregado e relegando, às mulheres, a esfera reprodutiva (KERGOAT, 2009). Para Scott (1995), o conceito de gênero acentua e explica as desigualdades pautadas entre feminino e masculino, e a autora rejeita o determinismo biológico do sexo e considera os sujeitos como resultado de construções sociais - parte do pressuposto de que os gêneros (masculino e feminino) percebem e vivenciam o mundo de maneira diferente, resultando em atuações diferentes e, portanto, influenciando na construção das relações de poder.

[...] O gênero é um elemento constitutivo de relações sociais baseadas nas diferenças percebidas entre os sexos e o gênero é uma forma primária de dar significado às relações de poder. As mudanças na organização das relações 
sociais correspondem sempre a mudanças nas representações do poder, mas a mudança não é unidirecional. (SCOTT, 1995, p. 86)

Entretanto Kergoat (2009) coloca que a divisão sexual do trabalho não é um dado imutável e que essas concepções variam fortemente no espaço e no tempo, sendo possível admitir, portanto, que as alterações presentes nas articulações e atuações das mulheres dentro dos movimentos sociais podem originar, no processo de construção da história, mudanças substanciais a respeito da participação política delas.

Problematizar em termos de divisão sexual do trabalho não remete a um pensamento determinista; ao contrário, trata-se de pensar a dialética entre invariantes e variações, pois, se supõe trazer à tona os fenômenos da reprodução social, esse raciocínio implica estudar ao mesmo tempo seus deslocamentos e rupturas, bem como a emergência de novas configurações que tendem a questionar a própria existência dessa divisão. (KERGOAT, 2009, p. 68)

Caminhando para um diálogo entre os territórios informais e a necessidade de se questionar o papel da mulher nesses cenários, Helene (2019) afirma que ainda são considerados escassos dados efetivos que comprovem a participação majoritária delas dentro dos assentamentos informais. A autora, entretanto, confirma a presença massiva das mulheres a partir de entrevistas que fez durante suas pesquisas e militâncias.

Souza (2013) se propôs a entender as razões que levam esta presença - seja na organização, seja na participação - a ser muito grande nos movimentos de moradia.

Ao buscar os porquês daquelas mulheres perderem horas de trabalho e deixarem outras responsabilidades de lado para estarem em uma reunião, comecei pelo único caminho que certamente me daria as respostas: pelas experiências dessas mulheres. [...] A casa, para a grande maioria das mulheres, é um bem de primeira necessidade. Não é apenas um local que lhes proporciona segurança e privacidade, mas é também - e sobretudo - onde elas exercem muitas das tarefas que socialmente lhes foram impostas, além de ser onde elas historicamente se reservam. [...] Ora, se o trabalho doméstico e de cuidados [ainda] é reservado prioritariamente à mulher e as condições de moradia são determinantes na realização desses trabalhos, é possível entendermos porque a moradia reveste-se como um bem de primeira necessidade para as mulheres em geral, tanto na esfera reprodutiva quanto produtiva. (SOUZA, 2013, p. 02-05)

Helene (2019) também coloca que um dos fatores que podemos associar a uma participação massiva do gênero em movimentos de moradia é a feminização da pobreza: uma mudança nos níveis de pobreza partindo de um viés desfavorável às mulheres ou aos domicílios chefiados por mulheres (MEDEIROS; COSTA, 2008), tendo, por indicador principal, o fato de o rendimento médio mensal de todos os homens com mais de 15 anos ser consideravelmente maior que o das mulheres. De acordo com a autora, com bases no Pnad/IBGE (2015), o rendimento médio mensal de todos os trabalhos dos homens com mais 15 anos de idade foi de $\mathrm{R} \$ 2.058$ e de $\mathrm{R} \$ 2.509$, sendo o segundo para os homens brancos, e de $\mathrm{R} \$ 1.567$ e de $\mathrm{R} \$ 1.027$, sendo o segundo para as mulheres negras. Assim, é perceptível como o mercado de trabalho não é acessado de forma igualitária entre os gêneros e tampouco entre as raças, visto que as mulheres negras recebem menos da metade do valor do salário dos homens brancos. Essas disparidades de raça também nos levam 
a uma reflexão importante a respeito das desigualdades internas à luta de gênero, que também será desenvolvida nesse artigo.

Esse fator, no que diz respeito à questão trabalhista, pode embasar a discussão sobre as mudanças nas formas de participação das mulheres nos movimentos sociais, incluindo as disparidades originadas pelo marcador da raça, assim como a mobilização para lutarem por maior independência e tomarem o espaço público como cenário das lutas, as quais perpassam a realidade condicionada socialmente e toda sua complexidade contemporânea.

\section{A formação da Ocupação Tereza de Benguela dentro do MTST}

O MTST surgiu com uma perspectiva de organizar os trabalhadores em meio urbano, almejando uma mudança em relação a seus direitos que são constantemente negados, como a questão da moradia (e todos suas relações com saúde, trabalho, educação), e estabelecendo pontos de contato com as lutas do Movimento dos Trabalhadores Rurais sem Terra (MST). Para Miagusko (2012), os militantes que deram origem ao MTST eram militantes liberados pelo MST para atuar no espaço urbano, no final da década de 1990, após a percepção da importância de buscar apoio nos meios urbanos, originada nas discussões ocorridas na Marcha Nacional por Reforma Agrária, Emprego e Justiça em $1997^{2}$. Entretanto transpor automaticamente as práticas do MST para o espaço urbano, sem nenhum tipo de reflexão a respeito do contexto em que se inserira, foi um problema observado pelos próprios militantes, fazendo com que a autonomia inicial gerasse o afastamento (e posterior desmembramento) entre os dois movimentos:

Quer dizer, uma base social completamente diferente, um espaço completamente diferente, [...] tem concentração de poder político e econômico. [...] As pretensões têm que ser outras, as formas de organização têm que ser outras e a forma de militância tem que ser outra. (Virgílio, 10/12/2005, apud MIAGUSKO, 2012, p. 258)

A partir das grandes diferenças percebidas entre os MTST e o MST, bem como por conta do esforço de se estabelecer enquanto um movimento diferenciado dos outros movimentos de moradia, o MTST não se define como um movimento delimitado exclusivamente pela luta da moradia, mas como um movimento popular urbano, que busca mobilizar e reivindicar as diversas frentes que permeiam a realidade desses moradores.

[...] Existe uma comunidade em Guarulhos - num primeiro momento nós entramos lá através da moradia [...] e agora estamos construindo o barracão para fazer oficinas, cinemas, atividades culturais. [...]" (Virgílio, 10/12/2005, apud MIAGUSKO, 2012, p. 259)

Dessa forma, é possível perceber nesses relatos que fazem parte da frente de luta do MTST não só a moradia, mas também outras necessidades que conformam a existência das pessoas nesses espaços urbanos, não minimizando a moradia como um fator secundário de luta, e sim equalizando outras questões como fatores essenciais para a sobrevivência e qualificação da vida - diversificando suas ações nas cidades e interseccionando as necessidades básicas do grupo.

${ }^{2}$ Para saber mais, ver Miagusko (2012). 
Em conversa, Alana ${ }^{3}$ colocou que o diferencial do MTST, atualmente, é a tecnologia que existe nas ocupações, sendo essa o acúmulo de conhecimento dos últimos 20 anos de existência sobre como é a melhor forma de fazer ocupação - na construção durante o período da madrugada, por exemplo. Esse conhecimento é extremamente relevante porque há muita ocupação que acontece nas periferias, mas muitas não conseguem permanecer, enquanto o MTST consegue se estabelecer durante algum tempo no território, alimentando o movimento e principalmente angariando novos militantes através do diálogo, trabalho esse que também é um ponto forte do movimento, de acordo com Miagusko (2012).

Essa perspectiva de estabelecer laços entre os movimentos sociais e a luta das classes desemboca em um olhar que, segundo Calió (s.d.), muitos estudiosos que abordam conceitos como segregação e direito à vida urbana o fazem considerando-os baseados nas classes sociais; entretanto dificilmente incorporam as questões de gênero nessas análises - mesmo que isso determine situações dos indivíduos dentro das relações urbanas. Essa análise, entretanto, não basta quando falamos de gênero, pois nem sempre reconhece as questões cotidianas presentes na cidade, as quais continuam oprimindo as mulheres e, de maneira mais específicas, as mulheres negras.

Em sua fala, Claudia afirma que aproximadamente $60 \%$ da coordenação do movimento do MTST é composto por mulheres e que, de uma maneira contrária aos naturalizados papeis sociais do homem e da mulher, na ocupação acontece um processo interno de disputa dos locais de atuação e ação política, demonstrando uma mudança inicial nas relações estabelecidas dentro do movimento.

Nós também temos um regimento interno que diz que todas as pessoas serão tratadas com igualdade, não é aceito qualquer discriminação, nem de raça, nem de credo, nem de nada, então as mulheres tem esse amparo, que diz que ela pode ocupar o lugar que a gente quiser, inclusive são as mulheres que fazem a segurança dos acampamentos. Quando pisamos na ocupação, a gente vê a inversão dos valores, tanto que as mulheres, por sermos maioria, a gente acha tempo na nossa dupla e tripla jornada e aceita a tarefa dentro do movimento, então a gente vê um número maior de mulheres atuando. Então agora é invertido, a mulher vai coordenar homens e mulheres e a cozinha ganha um outro papel na ocupação. (CLAUDIA, 2019)

Para Rosa (2007), há um crescimento significativo das mulheres nas disputas do território, ora impondo sua presença, ora rompendo barreiras e preconceitos que questionavam sua capacidade de se posicionar na sociedade. As grandes desigualdades pautadas pelo gênero, entretanto, são construções sociais que desequilibram valores e intensificam poderes e hierarquias existentes entre os sexos, refletindo, ainda, em diferenciações sociais entre homens e mulheres. Cupertino, Gomes e Lopes (2014) colocam que é importante reconhecer a liderança das mulheres nas ocupações urbanas como prova da possibilidade de se constituírem como sujeitos políticos, mas que é importante observar que nem sempre estão isentas da dupla jornada de trabalho imposta pelos valores patriarcais, visto que a indicação para os espaços de coordenação podem ser feitas justamente com base nas "aptidões femininas" para administrar e cuidar de um lar que serve à coletividade.

A fala da Claudia, entretanto, é importante pois preconiza e apresenta uma forma distinta de articulação dos trabalhos e papeis socialmente construídos. Nela, coloca-se a importância de se pensar em um papel de cuidado com a coletividade de maneira equalizada entre todos os

${ }^{3}$ Entrevista cedida a autora em 09/10/2019, em São Paulo. 
sujeitos, dividindo as responsabilidades da administração e do cuidado também com os homens, sujeitos que historicamente não são responsáveis pelas forças reprodutivas do trabalho. Em sua fala, Claudia também aponta que ainda há muita resistência dos homens dentro do MTST, visto que o machismo é estrutural e atinge a sociedade como um todo, principalmente por conta da criação desses espaços mais igualitários em relação às funções desempenhadas. Apesar disso, ela afirma que existe um esforço coletivo, amparado no regimento interno do movimento, para que esses processos sejam diminuídos continuamente e que seus integrantes sejam constantemente sensibilizados e estimulados a refletir sobre a importância dos espaços e ações comunitárias.

\section{O Matriarcado da Miséria: A Interseccionalidade entre Gênero e Raça}

A expressão "matriarcado da miséria" foi cunhada pelo poeta negro e nordestino Arnaldo Xavier para mostrar como as mulheres negras brasileiras tiveram suas experiências históricas marcadas pela exclusão, pela discriminação e pela rejeição social, e revelar, a despeito dessas condições, o seu papel de resistência e liderança em suas comunidades miseráveis em todo o país. (CARNEIRO, 2011, p. 130) Portanto, é importante olhar para as questões da perspectiva feminina a partir de todas as experiências das mulheres e suas especificidades e vivências que conformam sua experiência de mundo. Para Federici (2019, p. 151), "qualquer projeto feminista exclusivamente implicado com a discriminação sexual, sem situar a "feminização da pobreza" no contexto do avanço das relações capitalistas, estará condenado à irrelevância e à cooptação."

Desde a década de 1980, observamos a intensificação de um percurso científico e de mobilização brasileira que envolve tanto as ações vinculadas à prática do feminismo juntamente com uma incorporação de pautas específicas das mulheres negras (RODRIGUES, 2013). Crenshaw (2002) nos apresenta que essa construção da incorporação de determinados fatores na busca por uma equidade social originou-se a partir da Declaração Universal dos Direitos Humanos, combinada com diversas contribuições diretas da Convenção Internacional para Eliminação de Todas as Formas de discriminação Racial, levando-nos a compreender a lógica da interseccionalidade entre raça e gênero e buscando focalizar as diferenças em nome de uma maior inclusão.

A interseccionalidade é uma conceituação do problema que busca capturar as consequências estruturais e dinâmicas da interação entre dois ou mais eixos da subordinação. Ela trata especificamente da forma pela qual o racismo, o patriarcalismo, a opressão de classe e outros sistemas discriminatórios criam desigualdades básicas que estruturam as posições relativas de mulheres, raças, etnias, classes e outras. Além disso, a interseccionalidade trata da forma como ações e políticas específicas geram opressões que fluem ao longo de tais eixos, constituindo aspectos dinâmicos ou artigos do desempoderamento. (CRENSHAW, 2002, p. 177)

Essa interseccionalidade entre gênero e raça, mesmo não sendo fortemente pontuada na fala recuperada da Claudia, é uma realidade imbricada à ocupação e ao movimento do $\mathrm{MTST}^{4}$, que perpassam a luta dessas mulheres e condicionam diretamente os enfrentamentos das que

\footnotetext{
${ }^{4}$ Em um estudo sobre a Ocupação Zumbi dos Palmares (RJ) do MTST, a estudiosa Camila Moraes (2018) chegou a seguinte divisão étnico-racial a partir da aplicação de 446 questionários com famílias das ocupação: 34\% pretos; 48\% pardos; 16\% brancos; $1 \%$ amarelo e $1 \%$ sem resposta - considerando pretos e pardos, os negros somam $82 \%$ dos trabalhadores da ocupação. Essa afirmativa pode ser específica para a realidade do estudo, mas auxilia em um processo de compreensão geral da realidade do movimento. Para saber mais, ver Moraes (2018).
} 
vivenciam a ocupação, sendo explicitada também na escolha do nome, em referência à própria Tereza de Benguela 5 .

Quando empregamos o termo gênero, ou relações de gênero, estamos tratando das relações de poder entre homens e mulheres. [...] As diferenças de gênero são constituídas hierarquicamente: a construção social do ser homem tem um maior status que a construção social do ser mulher. O gênero é um termo relacional, que nomeia a interação entre o masculino e o feminino; portanto, o estudo de um é coadjuvante do estudo do outro. O conceito de gênero é uma categoria de análise de grande poder para explicar as desigualdades entre as pessoas. Não obstante, é apenas parte de uma construção social complexa de identidade, hierarquia e diferença. A raça, a etnia, a classe são outras categorias socialmente construídas que se intersectam com o gênero para determinar a localização social dos indivíduos. (SOARES, 2004, p.113-114)

Corroborando essa afirmativa, observamos que o espaço urbano é radicalmente caracterizado pelas relações desiguais entre ricos e pobres, sendo importante colocar, também, as contradições dentro das desigualdades sociais de sexo e gênero nas faixas mais pobres da sociedade, visto que ainda há processos que estruturam as questões étnico-raciais.

Tavares $(2015 ; 2017)$ utiliza o exemplo dos trabalhos de Maxine Molyneux, pesquisadora paquistanesa que apresenta o interesse das mulheres na Nicarágua nos anos 1980, para demonstrar como somos afetados diferentemente por nosso contexto de acordo com nossas subjetividades. A partir de seus resultados, a autora afirma que

Para as feministas [...] os interesses estratégicos das mulheres são avaliados como os verdadeiros interesses das mulheres, visto que são formulados a partir do que seria uma consciência de luta por emancipação feminina, ou seja, segundo formulações feministas. Um exemplo são as medidas que buscam garantir o controle da fertilidade e da proteção contra a violência masculina. 0 problema para a socióloga é que condicionar as mulheres a uma unidade de luta implica em solucionar os conflitos de classe. Apesar das mulheres sofrerem discriminação de gênero e estejam cientes disso, sofremos diferentemente conforme nossa classe social e raça e etnia, afetando nossas atitudes frente à luta emancipatória. Com isso, mesmo que tenhamos uma agenda em comum, o processo para a conquista desses interesses pode se diferenciar. (TAVARES, 2017, p. 5)

Diante dessas interseccionalidades, algumas autoras construíram sua trajetória acadêmica evidenciando a luta da mulher negra dentro de uma sociedade androcêntrica, que também ignora os processos de disparidades históricas nas lutas do gênero pautadas na etnia. Carneiro (2011) aborda, de maneira dialogada e contundente, como o racismo e o sexismo no Brasil estruturaram e ainda perpetuam as relações sociais e políticas brasileiras, pautadas na desigualdade. Para a autora, as mulheres negras assistiram, em diversos momentos, suas questões secundarizadas em uma luta - supostamente - mais ampla e universal pela igualdade de gênero, "[...] ou seja, o movimento feminista brasileiro se recusava a reconhecer que há uma dimensão racial na temática

\footnotetext{
${ }^{5}$ Claudia diz que a data em que a ocupação aconteceu é conhecida popularmente ou como a data de nascimento ou de falecimento de Tereza, que fora líder quilombola do século XVIII e que foi referência no enfrentando da escravidão na região do atual estado do Mato Grosso.
} 
de gênero que estabelece privilégios e desvantagens entre as mulheres" (CARNEIRO, 2011, p. 121) endossando, de maneira direta ou indireta, o matriarcado da miséria.

A lógica da incorporação da perspectiva de gênero, ou seja, focalizar a diferença em nome de uma maior inclusão, aplica-se tanto às diferenças entre as mulheres como às diferenças entre mulheres e homens. Há um reconhecimento crescente de que o tratamento simultâneo das várias diferenças que caracterizam os problemas e dificuldades de diferentes grupos de mulheres pode operar no sentido de obscurecer ou de negar a proteção aos direitos humanos que todas as mulheres deveriam ter. Assim como é verdadeiro o fato de que todas as mulheres estão, de algum modo, sujeitas ao peso da discriminação de gênero, também é verdade que outros fatores relacionados a suas identidades sociais, tais como classe, casta, raça, cor, etnia, religião, origem nacional e orientação sexual, são diferenças que fazem diferença. na forma como vários grupos de mulheres vivenciam a discriminação. Tais elementos diferenciais podem criar problemas e vulnerabilidades exclusivos de subgrupos específicos de mulheres, ou que afetem desproporcionalmente apenas algumas mulheres (CRENSHAW, 2002, p. 173)

É importante ressaltar que, dentro dos cenários de informalidade territorial e marginalidade socioeconômica, as mulheres mais afetadas estão ligadas a uma identidade racial específica, não sendo possível, portanto, desconsiderar esse fator no momento da reconstrução do processo de luta e resistência da mulher que ocupa o território e que resiste na sua permanência. Para além disso, a interseccionalidade na luta da Tereza de Benguela não se limita à perspectiva de raça e gênero, mas também se combina com outros aspectos de subordinação, como falta de acesso à moradia e à igualdade social.

\section{“A Gente não quer só Entregar Moradia, Nós Queremos que as Mulheres Não Sejam Mais Agredidas": A Violência Contra a Mulher}

A violência contra a mulher não é um fato novo e nem pertencente exclusivamente à sociedade contemporânea, mas, de acordo com Waiselfisz (2015), o que é recente é uma preocupação institucionalizada a respeito dela. No Brasil, mais nova ainda é a judicialização do problema, criminalizando essas práticas - em 2015, a Lei do Feminicídio (13.104/2015) passou a classificar como crime hediondo e com agravantes, quando em situações específicas consideradas como mais vulneráveis (gravidez, menor de idade, presença de filhos, entre outros). Para Marques (2017), essa presença da violência como fator constante na sociedade é um reflexo das práticas normativas hegemônicas que constituem nossas relações sociais.

A violência contra a mulher é uma expressão da sociedade machista em que vivemos e que impede que as mulheres exerçam seus direitos humanos mais básicos, como o direito à vida e o direito de ir e vir. As cidades, por sua vez, ao serem produtos históricos da construção humana refletem o opressão pela qual a sociedade se estrutura e, nesse sentido, é perceptível, no ambiente urbano, diversos traços de machismo em sua construção e vivência. (MARQUES, 2017)

Nos estudos de Waiselfisz (2015), é possível obter dados que constroem uma cronologia histórica a respeito da violência contra a mulher. Além disso, podemos observar que, mesmo estando em uma sociedade capaz de reconstruir continuamente a compreensão da multiplicidade 
de problemas enfrentados suas intersecções, existe um crescimento considerável nos casos de homicídio de mulheres entre os anos de 1980 e 2013, conforme Gráfico 1, enfatizando que essa realidade ainda é extremamente marcante e determinante nas relações e papeis sociais.

Gráfico 1 - Evolução da taxa de homicídios de mulheres (a cada 100mil) entre 1980 e 2013

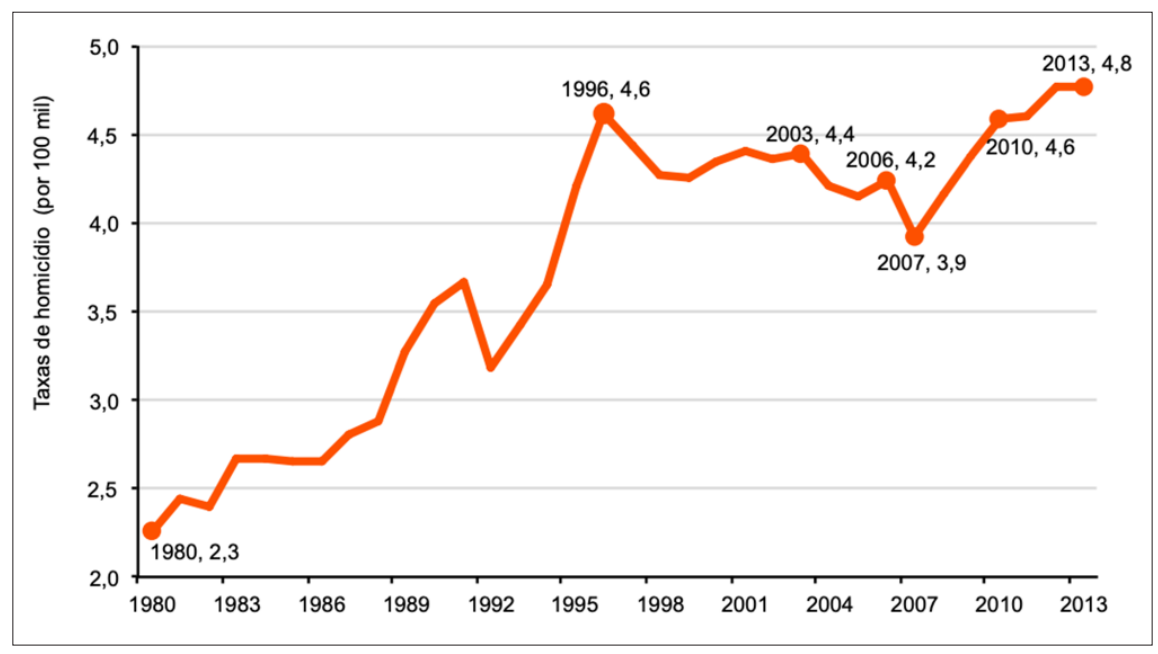

Fonte: Waiselfisz, 2015

Claudia explica que uma das situações que começaram a explicitar a importância de abordar a violência contra as mulheres dentro do movimento se passou em 2016 - aconteceram algumas agressões na ocupação Esperança Vermelha, também vinculada ao MTST, onde uma mulher foi agredida pelo companheiro e exposta na frente de todos da ocupação, enquanto o companheiro buscava justificar o ato através da declaração de que ela o estava traindo. A organização da Esperança Vermelha ficou indignada e afirmou que, independente de traição ou qualquer outro ato, nada justificava aquela agressão; entretanto, de acordo com Claudia, várias pessoas assistiram à cena com muita desafetação, demonstrando a naturalização da violência contra a mulher. A partir dessa experiência, a liderança enxergou a importância de criar espaços onde pudessem acontecer rodas de conversa e conscientização coletiva para diminuir os casos de violência e, juntamente a isso, a compreensão de que essa violência seria justificada por alguma razão. Em uma primeira conversa, o espaço foi aberto apenas para as mulheres poderem desabafar e estabelecer laços de confiança.

Na segunda roda de conversa, as mulheres deixaram muito claro que tinham dificuldade de conversar com os homens dentro de casa e apontaram essa necessidade de conversar com os homens. Assim, foram feitas três rodas de conversa com homens também, e no final, eles admitiam algumas questões que antes eles não admitiam. (CLAUDIA, 2019)

As falas acima, trazidas pela Claudia, expõem situações presentes no movimento, mas que também o constituem como um produto estruturado pela sociedade patriarcal e machista em que vivemos, já que os índices de violência cometida dentro de casa, no Brasil, ainda são muito altos, perpassando o movimento e nele refletindo diretamente.

Dentre as variadas formas de agressão, a expressão mais extrema é o homicídio. De acordo com o Mapa da Violência 2015, aproximadamente 7 mulheres são assassinadas por dia, tendo como homicida, um familiar. Esse número representa 
a totalidade de mortes, ou seja, contempla todos os casos de homicídio (morte no trânsito, por tráfico de drogas etc.). Destacamos. [...] o homicídio praticado por (ex)parceiro/marido/namorado, uma vez que se maximiza a crueldade da violência, na medida em que além de acontecer no âmbito da residência da vítima, é praticada por alguém que deveria contri- buir para a qualidade de vida e segurança desta mulher. Nestes casos, também de acordo com o Mapa da Violência 2015, a média é de 4 feminicídios por dia. (WAISELFISZ, 2015 apud BERTOLIN; ANDRADE, 2017)

No cruzamento do depoimento com os dados obtidos, percebemos como a violência não se expressa da mesma forma entre homens e mulheres, constituindo um cenário de risco muito mais constante para elas, diante das várias formas de violência que cerceiam sua existência. É importante entender que essa expressão de violência se dá de maneira diferente entre os gêneros e, retomando a perspectiva da interseccionalidade, observamos que essa violência se expressa distintamente entre as mulheres, visto que as mulheres negras estão mais suscetíveis a sofrerem violência do que as brancas - violência essa vinculada à opressão dupla, do machismo e do racismo, como atestam os dados do Mapa da Violência de 2015, citado por Waiselfisz. "As taxas de homicídio de mulheres brancas caíram 11,9\%: de 3,6 por 100 mil brancas, em 2003, para 3,2 em 2013; [...] taxas das mulheres negras cresceram 19,5\%, passando, nesse mesmo período, de 4,5 para 5,4 por 100 mil."(WAISELFISZ, 2015, p. 31). Essa realidade também é corroborada por Crenshaw (2002) quando afirma que os exemplos mais conhecidos da opressão interseccional são as violências contra as mulheres baseadas na raça ou na etnia.

Para Waiselfisz (2015), é possível concluir que: i) com poucas exceções geográficas, a população negra é vítima prioritária da violência homicida no Brasil; ii) as taxas de homicídio da população branca tendem, historicamente, a cair, enquanto aumentam as taxas de mortalidade entre os negros ${ }^{6}$; iii) por esse motivo, nos últimos anos, o índice de vitimização da população negra cresceu de forma drástica.

Os dados acima também reforçam a discussão sobre a interseccionalidade presente nas lutas históricas das mulheres negras, narradas por Davis (2016), que buscavam se estabelecer não só enquanto mulheres de direitos, mas também se empreendiam nas disputas sociais vinculadas aos direitos do povo negro.

Mais do que quaisquer outras mulheres envolvidas na campanha contra a escravidão, as irmãs Grimké instavam a constante inclusão do tema dos direitos das mulheres. Ao mesmo tempo, argumentavam que as mulheres nunca alcançariam sua liberdade independentemente do povo negro. "Quero ser igualada ao negro", disse Angelina em uma reunião de mulheres patriotas que apoiavam a Guerra Civil, em 1863. "Enquanto ele não tiver seus direitos, nós não teremos os nossos." (DAVIS, 2016, p. 59)

Claudia afirma também que a Tereza de Benguela foi motivada, em sua existência, a partir de um conhecimento em macroescala da situação das ocupações do MTST, ampliando a perspectiva e importância de criar espaços de apoio dentro do movimento.

\footnotetext{
${ }^{6}$ Nota do autor: "Recém em 1996, o MS introduz nas Declarações de Óbito o quesito raça/cor, com enorme subnotificação até fins do século. Por esse motivo, começamos a trabalhar o tema a partir do ano 2000. O MS utiliza as mesmas 5 categorias que o IBGE, considerando a população, por autodeclaração, branca, preta, amarela, parda e indígena. Nos Mapas da Violência, utilizamos duas categorias: branca e negra, sendo esta última resultante da somatória de pretos e pardos."
} 
Em 2017, a gente fez uma ocupação na Paulista para cobrar o governo na verba que estavam paradas para a moradia - nossos projetos foram parando/emperrando. Ocupamos durante 22 dias a Paulista e no intervalo, enquanto a gente esperava, a gente propôs muita atividade de formação política também com as mulheres de outros coletivos que foram feitas naquele momento. Juntando essas experiências, nós entendemos que não tinha mais como ficar sem um lugar que fosse só nosso, porque ela [a violência] vinha de fora, mas estava dentro também da militância. Esse era o exato momento para construir o espaço. Outro fator que fortaleceu isso foi que uma pesquisa socioeconômica na ocupação Copa do Povo, dizia que 70\% das mulheres tinham sido vítimas ou testemunhas de violência contra mulher. (CLAUDIA, 2019)

Foi então, a partir dessa perspectiva de entendimento sobre a situação das mulheres dentro do movimento, que a coordenação estadual aprovou o processo de apoiar as mulheres nessa luta e, no dia 25 de novembro de 2017, aconteceu a ocupação na COHAB José Bonifácio7.

Anteriormente, o edifício de propriedade da Companhia Metropolitana de Habitação de São Paulo (COHAB) se encontrava abandonado e era utilizado como depósito de lixo e como ponto de tráfico e consumo de drogas, mas a ocupação passou a dar uma função social ao espaço, estabelecendo atividades práticas que respondem às necessidades reais das mulheres do movimento. A partir da oferta de apoio para mulheres que sofreram agressões ou maus tratos, compreendemos o argumento abordado por Miagusko (2012) de que o MTST não sanciona ações vinculadas exclusivamente à moradia, mas também às várias frentes que se articulam para permanência urbana, como a segurança das mulheres do MTST.

\section{“Ela Pode Tomar as Rédeas da Própria Vida": Trabalho, Renda e Independência Financeira}

A princípio, pela fala da Claudia, entendemos que a ocupação Tereza de Benguela se reformulou em relação a seus objetivos, deixando de ser, como imaginado originalmente, uma casa de acolhimento (que funcionaria como uma casa-abrigo) ${ }^{8}$, para ser um centro de convivência, por conta de todos os riscos que as mulheres sofreriam se buscassem uma permanência efetiva no local. Entretanto, enquanto centro de convivência, as mulheres ainda precisavam voltar para suas casas e, com isso, poderiam ser novamente vítimas da violência que fazia com que buscassem o local. Por conta disso, um dos enfoques que é percebido na fala de Claudia, quanto às atividades da Tereza de Benguela, é a atenção dada não só à violência que as mulheres sofrem, mas também à formação e à geração de renda para que essas mulheres sejam capazes de buscar autonomia financeira e conseguirem emancipação.

Começamos a desenvolver as atividades com as mulheres; a principio, queríamos que fosse uma casa de acolhimento, mas com o passar dos dias, com o acolhimento que fornecíamos, a gente descobriu que tanto nós quanto elas estávamos desprotegidas, porque o agressor podia chegar lá e cometer qualquer coisa com ela, matar elas ou nós mesmo.

\footnotetext{
${ }^{7}$ A princípio, de acordo com Claudia, haveria duas ocupações nesse mesmo dia, uma na zona leste e uma na zona sul, mas essa segunda não deu certo e as mulheres que iam ocupá-la foram fortalecer a ocupação do edifício da COHAB.

${ }^{8}$ As Casas-Abrigo são locais seguros que oferecem moradia protegida e atendimento integral a mulheres em risco de morte iminente em razão da violência doméstica. É um serviço de caráter sigiloso e temporário, onde as usuárias permanecem por um período determinado, durante o qual deverão reunir condições necessárias para retomar o curso de suas vidas. Informações retiradas do Observatório da Mulher Contra a Violência, disponível em https://www12.senado.leg.br/ institucional/omv/acoes-contra-violencia/servicos-especializados-de-atendimento-a-mulher
} 
Então nós decidimos que seria só um centro de convivência/centro de referência. A gente fez muita atividade nessa casa e logo no primeiro dia, após a limpeza, fizemos uma roda de conversa, sobre nosso corpo e sobre a violência que sofríamos. Então, nesses primeiros cinco meses antes de sermos reintegradas, propomos atividades em três eixo: saúde, geração de renda e formação política e cultural para as mulheres. Abríamos as terças, quintas e sábados. Fizemos muitas atividades, não da nem para falar todas, mas essas sobre geração de renda é que faz com que a mulher perceba que tem valor, que ela pode tomar as rédeas da própria vida, podendo mudar a situação através da geração de renda e independência financeira. (CLAUDIA, 2019)

Federici (2019) discute a perspectiva de que, após a implicação do capitalismo como condicionante de algumas sociedades ${ }^{9}$, a mulher passa a ter sua força de trabalho, anteriormente produtivo, para servir ao capital com o trabalho reprodutivo - o trabalho de manutenção da casa, da família e do homem, esse ainda com sua força de trabalho (produtivo) valorizada. Diante disso, no livro "O Ponto Zero da Revolução", ela abordará, a partir de diversos textos escritos, a importância do reconhecimento do trabalho doméstico, assim como essas possíveis transformações e relações entre trabalho produtivo e reprodutivo, como forma de alterar as sujeições e apropriações vivenciadas pelas mulheres por parte do patriarcado.

Está claro que a recusa das mulheres em ser trabalhadoras não remuneradas dentro de casa [na perspectiva norte americana da década de 1970] provocou mudanças importantes na organização da reprodução e nas condições do trabalho feminino. 0 que estamos testemunhando é a crise da tradicional divisão sexual do trabalho, que confinava as mulheres ao trabalho reprodutivo (não assalariado) e os homens à produção (assalariada) de mercadorias. Todas as relações de poder entre homens e mulheres foram construídas nessa "diferença”, já que a maioria das mulheres não teve alternativa a não ser depender de homens para sua sobrevivência econômica e se submeter à disciplina que vem com essa dependência. (FEDERICI, 2019, p. 109)

A luta pela formação e capacitação das mulheres da Tereza de Benguela é uma estratégia extremamente relevante como forma de estabelecer uma luta das mulheres relacionada a uma independência financeira e, consequentemente, a uma possibilidade de se emancipar de situações às quais estão sujeitas, por conta da dependência financeira e/ou familiar que cerceiam suas decisões. A afirmativa de Silvia Federici corrobora os relatos da entrevista feita com Alana e sua percepção sobre sua atuação junto ao MTST: muitas mulheres não saíam de casamentos tidos como insatisfatórios exatamente pelo estabelecimento de uma dependência organizacional e que, por conta das várias limitações - incluindo a de capacitação técnica para exercer um trabalho externo ao doméstico -, essas mulheres permaneciam nessas relações.

Dialogando com essa perspectiva trabalhista, Kergoat (2009) afirma que a divisão sexual do trabalho, baseada no capitalismo, destina às mulheres as funções categorizadas como inferiores e não entendidas como trabalho - sem valor econômico -, seguindo o princípio das atividades ditas como masculinas e femininas. Dentre as atividades femininas, tem-se o trabalho relacionado ao cuidado interno à casa, o qual é invisibilizado e articulado como parte da "essência feminina", não apresentando remuneração. "A noção de gênero nos permite melhor compreender que a

\footnotetext{
${ }^{9}$ Para mais sobre essa discussão, ver: FEDERICI, S. Calibã e a bruxa: Mulheres, corpo e acumulação Primitiva. São Paulo: Editora Elefante. 2017
} 
divisão sexual do trabalho nada mais é que uma construção social desigual de valor e de poder que confirma a existência de uma hierarquia entre os sexos". (ROSA, 2007)

Assim, a divisão sexual do trabalho e a opressão de gênero são questões indissociáveis na formação do capitalismo e da sociedade na qual nos inserimos. A respeito da remuneração das mulheres, já abordada e constatada que é consideravelmente menor que a dos homens, seu trabalho produtivo é completamente desvalorizado e, portanto, suas condições de permanência e desenvolvimento na carreira são impedidas também pelo trabalho reprodutivo determinado a elas. (HELENE, 2019) Essa falta de remuneração, então, passa a ser uma condicionante para as decisões de emancipação possíveis dessas mulheres, emancipação que as atividades da Tereza de Benguela buscam alcançar.

Quando a ocupação sofreu a reintegração de posse ${ }^{10}$, em abril de 2018, houve uma organização coletiva de todo o MTST, mas principalmente das mulheres vinculadas ao movimento, buscando reviver o espaço que estava sendo estabelecido como ponto de apoio coletivo às mulheres do movimento.

Ficamos de abril até julho [de 2018] peregrinando lá [na COHAB], toda semana íamos ver algum imóvel que eles mostravam pra gente [para instalar a ocupação em outro local], mas ou estava muito deteriorado, ou tinham moradores de rua. [...] Dia 20 de julho, fomos para nossa última tentativa. Chegamos lá e eles nos disseram que estávamos rodando em círculos, mas na verdade, quem estava nos enrolando, eram eles. A partir daquele momento, nós ocupamos a COHAB, colando bandeiras do MTST e da ocupação Tereza de Benguela]; eles ficaram olhando um para o outro sem reação. [...] Um senhor que era importante na COHAB pediu 5 minutos para negociar e enquanto ele saiu da sala, propomos que nos devolvessem nosso antigo endereço, porque estava parado, lá tínhamos condição de continuar os projetos - já que havíamos ajeitado o espaço, e nos tiraram de lá sendo que fazíamos um trabalho muito importante. Demos a palavra que assim que fosse encontrado um local definitivo, sairíamos do espaço. Pediram 24 horas para poder negociar com o jurídico e deu tudo certo. Em agosto de 2018, voltamos para o local. (CLAUDIA, 2019)

Após cinco meses da reintegração de posse, em setembro de 2018, a Ocupação Tereza de Benguela retornou ao espaço onde estavam anteriormente, retomando a luta de garantia de oferta de amparo e dignidade da vida das mulheres. A possibilidade de manutenção do espaço de formação e capacitação profissionalizante possibilitou a retomada das atividades e ações em busca da independência financeira dessas mulheres.

\section{“Que Nosso Povo Tenha Espaço e Que Se Tornem Protagonistas Nessa Luta": Feminismo Popular e o Fazer Política}

Collins (2017, p. 14) coloca que a discussão da interseccionalidade tem aumentado significativamente nas pesquisas e contribuições científicas, mas que é importante entender que "liberdade, equidade, justiça social e democracia participativa devem constituir as ideias centrais do feminismo", permitindo-nos entender que as ideias relacionadas ao "fazer política", identificado

\footnotetext{
${ }^{10}$ De acordo com a fala da Claudia, a ocupação sofreu reintegração de posse a pedido da COHAB, dona do espaço onde se localizava a mesma. 0 mandado foi obtido em processo de 2006, muito antes da existência da ocupação, contra um antigo inquilino, fazendo com que a reintegração seja entendida como uma violação dos direitos das ocupantes e beneficiadas do apoio oferecido, uma vez que a ocupação estava em processo de regularização e a COHAB havia garantido às ocupantes a possibilidade de permanecer com as atividades de acolhimento.
} 
dentro das narrativas, também se posicionam como uma pauta do feminismo interseccional e que se consolidam como um aspecto relevante para a discussão.

O Brasil moderno e o cidadão nele definido se instituíram às custas de uma dissolução das referencias últimas da ação e participação coletivas que constroem um horizonte democrático. [...] É isto o que constitui o significado primeiro dos movimentos sociais: ao proporem a autonomia da ação coletiva, eles trabalham também para a valorização de uma sociedade finalmente política e aberta aos conflitos através de uma referência democrática: nem mais párias à política, nem mais súditos do Estado, mas cidadãos. (PAOLI, 1991, p. 126)

A autonomia coletiva almejada pelos movimentos, de acordo com a autora, dialoga diretamente com as estratégias de ação e formação política do MTST. Segundo Alana, isso acontece porque o movimento se constitui de diversas camadas, e que, partindo das camadas mais exteriorizadas (as que estamos mais acostumados a ver, relacionadas com uma luta coesa por moradia) até as camadas mais internas (que podem ser entendidas nas pequenas interações coletivas que acontecem no movimento e que, a princípio, não são a grande "máquina" de fazer política, apesar de também produzirem uma política própria), o MTST busca por essa sociedade democrática e justa.

Em relação às lutas femininas, na fala de Claudia, é perceptível que as mulheres dentro da ocupação buscam por um feminismo que leva em consideração as reivindicações e realidade social das mulheres negras da periferia, que lutam diretamente pela moradia, porque são elas que sofrem majoritariamente pela falta de política pública de saúde, de transporte, de educação e moradia. Por essa razão, Claudia compreende que a luta das mulheres que estão dentro do movimento e que também usufruem da Tereza de Benguela, é transversal e interseccional. "Nós somos territorialistas, então toda vez que fazemos uma ocupação, nos também vamos lutar por aquele bairro, por transporte, por creche, por escola, por parques, então esse é nosso espaço, para que a gente pertença à cidade." (CLAUDIA, 2019)

O "fazer política" dentro do MTST é percebido, a partir das falas tidas como essenciais para o trabalho, como uma prática corriqueira e completamente ramificada em relação às várias atividades que permeiam as ações do movimento. Miagusko (2012) coloca que o processo de ocupar é extremamente formativo e que perpassa toda a existência do MTST, sendo que os trabalhos de base para a instalação de um acampamento, assim como a mobilização interna, a vivência nas atividades e as necessidades e similaridades enfrentadas (seja pelos acampados ou por futuros integrantes do movimento), são de uma força imprescindível para a formação dos militantes. Esses processos informativos e coletivos vão se apresentando, na fala da Claudia, como espaços passíveis de serem repensados a partir de uma perspectiva que busque maior igualdade e equidade nas relações de gênero dentro do movimento.

Para gente, é importante porque os espaços marcados pelo patriarcado sofrem uma mudança de valor muito grande e assim a gente consegue continuar nossa luta, reconstruindo nossas relações humanas. Nós temos essa prática de se o homem fala, a mulher também tem que falar; se a mulher organiza o espaço, o homem também tem que organizar. Então, dentro de um microcosmo que é uma ocupação, a gente está tentando viver de uma maneira que a gente almeja, mais justa e mais igualitária e que seja um processo de transformação. (CLAUDIA, 2019) 
Na conversa da Alana, é perceptível a concordância com esse processo formativo do MTST como forma de estabelecer laços internos e externos ao movimento. Além disso, sua contribuição é interessante, principalmente, pois seu olhar é focado em uma esfera menos tradicional no entendimento do "fazer política", que são os espaços da cozinha do acampamento, os quais, na sua opinião, também podem ser vistos como um verdadeiro espaço de produção crítica e criação de identificações coletivas. Dentro do próprio MTST, a cozinha, espaço tido historicamente como subjugado e determinado à atuação da mulher, é de extrema relevância tanto para o funcionamento concreto do acampamento (na produção de alimento) como para o funcionamento intangível e cíclico do movimento. De acordo com Alana,

é a primeira coisa a ser construída em um acampamento (até pelo ponto de vista judicial). Então sem cozinha, não tem ocupação, desde a primeira noite até no dia a dia. E essa cozinha produz política - não é só um espaço onde ficam fazendo comida - ela tem uma concepção relacional muito forte. (informação verbal)

Essa concepção relacional não é tida como exclusiva para dentro do movimento, visto que, na fala da Alana, é perceptível que quem está na cozinha acaba conhecendo as necessidades e especificidades dos acampados, mas também é importante para além do acampamento, pois é a partir desse espaço, tido como virtuoso e de produção alimentar, que se estabelecem laços mais próximos com o entorno do acampamento. Alana afirma que:

Quando acontece um acampamento um terreno, tem a expectativa que as pessoas do entorno se integrem, mas não é tão simples, porque mesmo na periferia, as pessoas ainda acham isso perigoso. Então é um trabalho muito meticuloso de se abrir para que os vizinhos entrem na ocupação e vejam que ali está tudo bem e a cozinha, é o lugar ideal para esse contato com o exterior - pois a relação de se alimentar é muito simétrica (todos comem, não há hierarquia). A partir disso, abre-se conversas. (informação verbal)

Alana esclarece então que, sem a cozinha, o acampamento não aconteceria, não só pelos seus papeis de produção, mas também por ser o espaço de abertura para qualquer forma de interação, seja dos acampados, seja dos moradores do entorno. Ela afirma que "na cozinha as atividades são mais organizadas e são muito cheias e é exatamente isso que sustenta o funcionamento da ocupação. [...] Tudo que acontece na cozinha é bonito e é forte exatamente pela imprevisibilidade." (informação verbal) É na cozinha que as experiências das mulheres (sofrimentos pessoais, casos de violência, problemas gerais) aparecem com frequência, portanto, não há pudor em relação aos relatos, o que forma uma produção compartilhada das vivências - para a entrevistada, é uma forma mais orgânica de política, menos pautada nos discursos tradicionais do movimento e mais próxima das experiências vivenciadas e identificações estabelecidas.

Essa relação de troca e de reflexão coletiva, que acontece nos espaços internos à ocupação, é de extrema relevância, pois é a partir dessa relação que, de acordo com Silva (2016a), estabelecem-se identificações com a prática da luta em prol das mulheres.

Uma pessoa pode se identificar como mulher a partir de ideias não feministas, ou seja, compreender sua existência dentro do padrão social mulher, reforçando-o na sua prática cotidiana. Entretanto, esta possibilidade dificilmente se dá a partir de uma reflexão, de um exercício de pensamento sobre a realidade, tenderá a ser uma vivência no interior do senso comum. Perceber-se como mulher, a partir de uma perspectiva crítica, é, portanto, parte do processo de 
identificação feminista. Isto corre com muitas mulheres em diferentes tempos de sua existência. Algumas de revoltam com a educação diferenciada entre os sexos nas suas famílias desde a infância ou com o preconceito racial que, como negras, vivem nas escolas. (SILVA, 2016a)

Esse debate pode ser assentado com as questões apresentadas por Rancière (1996): a potência humana é a chave para o conflito e é nesse conflito que se estabelece o "fazer política". Para o autor, fazer política não está vinculado à produção e compreensão de mundo originada no Estado, mas sim ao processo de contestar a ordem naturalizada, ou seja, sua base está exatamente na existência da reinvindicação. Devemos, nessa lógica analítica, "considerar as identidades individuais ou coletivas como formações indivisíveis que, ao se conflitarem com outras identidades, demandarão um reordenamento dos processos identificatórios particulares e do ordenamento social como um todo." (MACHADO, 2013, p. 266)

A emancipação não [é] simplesmente um grande movimento coletivo com objetivos precisos, mas, sobretudo, a série de transformações mediante as quais os indivíduos começam a transformar suas vidas e se tornam capazes de fazer coisas que pensavam que não poderiam fazer. (RANCIÈRE, 2018)

Dessa maneira, entendemos que tais identificações, que partem de uma formação de comunidade política originadas nas percepções individuais dos sujeitos, estão vinculadas a uma lógica do comum; a uma lógica do compartilhamento de identidade e de questões comuns que não necessariamente estão circundadas pelas categorias que tendemos a considerar como definidoras dos campos de trabalho.

Essa questão analítica pode ser entendida também como forma de pensarmos o feminismo enquanto produção de política a partir de, não necessariamente, uma categoria previamente estabelecida (mulheres), mas uma junção de vivências, experimentações de mundo e ações que corroboram uma articulação em torno de um interesse comum, transformando esse processo em uma luta interseccional.

Silva (2016a) coloca que, na experiência brasileira, o feminismo hegemônico não pode ser considerado apenas como um feminismo de mulheres brancas, intelectuais e de classe média, mas que deve ser pautado fundamentalmente em um tipo de representação e luta que se identifique com aquelas de classes populares, vistas enquanto sujeitos políticos que atuam e lutam pela integração das mulheres na ordem originalmente dominante. Essa compreensão, portanto, pode ser entendida como base para um feminismo popular, que não necessariamente está vinculado à categorização de uma luta revolucionária, e sim às bases de identificação coletiva e compartilhada de valores e ideais comuns, observados nas práticas da ocupação Tereza de Benguela.

\section{Considerações Finais}

De forma inicial, esse trabalho pondera sobre a correlação entre a organização feminina dentro de um movimento social urbano em prol de um fortalecimento coletivo para mulheres, assim como pela oferta de serviços estruturalmente negados a elas. Dentre algumas questões presentes na discussão, sobressaem alguns pontos importantes e que valem a pena serem reforçados.

A formação do sujeito político, bem como seu empoderamento, é reforçado a partir da participação nos movimentos sociais - questão que permeia e transpassa a discussão de gênero. As mulheres militantes ou participantes de movimentos passam a lutar, de acordo com Helene 
(2019), contra uma segregação socioespacial generificada, marcada pelo capitalismo e, também, pelas questões de gênero e raça.

A questão da mulher trabalhadora, de classe popular, nem sempre é vista como uma atuação feminista pois, de acordo com Silva (2016b), a visão predominante de feminismo exige uma identificação proclamada, onde a mulher individualmente se declare como tal. Essa visão só é aceitável, para a autora, quando observamos o indivíduo enquanto sujeito sozinho na luta e que, assim, precisa levantar uma bandeira para poder se inserir na discussão. Na ocupação Tereza de Benguela isto não se observa, visto que aquilo que aproxima as mulheres não está no seu posicionamento verbalizado, mas nas experiências vivenciadas de maneira coletiva. Portanto a questão da articulação feminista pode ir muito além de uma declaração ou adesão formalizada ao movimento, podendo se dar a partir de uma identificação coletiva e uma compreensão de que as reflexões que são estabelecidas por um sujeito podem ser, muitas vezes, compartilhadas, podendo alcançar de maneira mais significativa as mudanças concretas de realidades específicas.

O elemento/a experiência que permeia as falas das nossas interlocutoras e que dialoga com a realidade observada nas incursões de campo, sendo também o disparador ou o motivo para o surgimento da ocupação, é a violência que acomete as mulheres ligadas ao MTST. Essa violência perpassa e estrutura a sociedade como um todo, incluindo as formas de organização popular, permitindo-nos refletir sobre a motivação da existência da ocupação Tereza de Benguela. A estruturação desta ocupação responde menos diretamente ao modus operandi do movimento - que não é um movimento originalmente formado a partir da pauta feminista - mas como forma de estabelecer um espaço seguro às mulheres, fortemente atrelada a uma estratégia de sobrevivência desses militantes. Outro aspecto relevante, importante de ser trazido como fechamento dessa discussão, é o posicionamento de Collins (2017) quando aborda que a lógica original do feminismo interseccional busca a promoção de políticas emancipatórias em busca de uma sociedade mais justa, que dialoga diretamente com as lutas narradas por Claudia como pauta importante da Ocupação Tereza de Benguela.

Essas motivações de busca pelos direitos das mulheres, o combate à opressão de gênero, em suas diversas formas e materializações, e a procura por uma sociedade mais igualitária também podem ser vistas na organização do Primeiro Encontro Estadual das Mulheres Trabalhadoras Sem Teto, realizado em outubro de 2019, pelas mulheres do MTST. Mesmo se considerarmos que o movimento existe há mais de 20 anos e que esse evento tenha acontecido, pela primeira vez, em 2019, entender as perspectivas de sensibilização dessas mulheres, assim como a compreensão de uma realidade cada vez mais complexa e dinâmica, que interfere e/ou condiciona suas vidas, é um processo que pode ser visto, em um primeiro momento, como lento, mas concretiza um avanço significativo, não só nas discussões e pautas do movimento, mas essencialmente na formação pessoal e coletiva dessas integrantes.

Essas possibilidades dialogam quando Souza (2013) coloca que as mulheres dos movimentos de moradia em geral podem, em um primeiro momento, engajar-se nas lutas por causa, principalmente, das contradições de gênero baseadas na divisão do trabalho, pelas conquistas de moradia e por outros direitos sociais que proporcionam maior seguridade para o trabalho reprodutivo, o qual foi construído socialmente como de sua responsabilidade. Depois, entretanto, é possível que, "na medida em que participam ativamente deles, se empoderem para reivindicarem mudanças na produção do espaço que possam mitigar aquelas mesmas contradições. (SOUZA, 2013, p. 9). 


\section{Referências}

ALONSO, Angela. As teorias dos movimentos sociais: um balanço do debate. Lua Nova, São Paulo, v. 76, p. 49-86, 2009.

BERTOLIN, Patrícia Tuma Martins; ANDRADE, Denise Almeida. Violência contra a mulher e feminicídio: a urgente necessidade de informação atualizada e contínua. In: Instituto Brasileiro de Direito Urbanístico (org). Direito à Cidade: uma outra visão de gênero. São Paulo: IBDU, 2017.

CALIÓ, Sônia Alves. Incorporando a questão de gênero nos estudos e no planejamento urbano. [s.l.] [s.n.t.] [s.d.]

CARMO, Carolina Guida C. Sobrevivência urbana através de ocupações organizadas por (e para) mulheres. URBS. Revista de Estudios Urbanos y Ciencias Sociales, v. 9, n. 1, p. 161-170. 2019.

CARNEIRO, Sueli. Racismo, sexismo e desigualdade no Brasil. São Paulo: Selo Negro, 2011.

CHAUÍ, Marilena. Participando do debate sobre mulher e violência. In: Várias autoras. (Org).

Perspectivas Antropológicas da Mulher. Rio de Janeiro: Zahar Editores. 1985. pp. 25-62.

CRENSHAW, Kimberlé. Documento para o encontro de especialistas em aspectos da discriminação racial relativos ao gênero. Estudos Feministas. v. 10, n.1, p. 171-188. 2002.

COLLINS, Patricia. Se perdeu na tradução? Feminismo negro, interseccionalidade e política emancipatória. Parágrafo. v. 5, n. 1, p. 6-15. 2017.

DAVIS, Angela. Mulheres, raça e classe. 1. ed. - São Paulo : Boitempo, 2016

FEDERICI, Silvia. O ponto zero da revolução: trabalho doméstico, reprodução e luta. São Paulo: Elefante, 2019.

GOHN, Maria da Gloria. Movimentos sociais na contemporaneidade. Revista Brasileira de Educação. v. 16 n. 47.p. 333-361. 2011

HELENE, Diana. Gênero e direito à cidade a partir da luta dos movimentos de moradia. Cad. Metrop., São Paulo, v. 21, n. 46, p. 951-974. 2019. https://doi.org/10.1590/cm.v21i46.41949

KERGOAT, Danièle. Divisão sexual do trabalho e relações sociais de sexo. In HIRATA, H.; FRANÇOISE L.; LE DOARÉ, H.; SENOTIER, D. Dicionário Crítico do Feminismo. 1. ed. São Paulo: Ed UNESP, 2009. P. 67-75

LOPES, Claudiane.; XAVIER, Indira. Ocupações de mulheres: luta e solidariedade. A verdade. 31 de outubro de 2017. Disponível em averdade.org.br/2017/10/ocupacoes-de-mulheres-luta-esolidariedade/.

MACHADO, Frederico Viana. Subjetivação política e identidade: contribuições de jacques rancière para a psicologia política. Rev. psicol. polít., São Paulo, v. 13, n. 27. p. 261-280. 2013 .

MARQUES, Helena Duarte. A luta das mulheres nunca matou ninguém. O machismo mata todos os dias. In: Instituto Brasileiro de Direito Urbanístico (org). Direito à Cidade: uma outra visão de gênero. São Paulo: IBDU, 2017.

MEDEIROS, Marcelo; COSTA, Joana. O que entendemos por “feminização da pobreza”? Centro Internacional de pobreza. N. 58, 2008.

MIAGUSKO, Edson. Movimentos de moradia e sem-teto em São Paulo: experiências no contexto do desmanche. São Paulo: Alameda, 2012. 
MORAES, Camila. O problema da moradia no brasil tem cor? In: XVI Encontro Nacional de Pesquisadores em Serviço Social. Anais [...] Vitória: ABEPSS. 2018.

PAOLI, Maria Celia. As ciências sociais, os movimentos sociais e a questão do gênero. XIV Encontro Anual da Anpocs. Anais [...] Caxambu, Minas Gerais. 22-26 de outubro de 1990.

PAOLI, Maria Celia. Movimentos sociais, cidadania, espaço público: perspectivas brasileiras para os anos 90. Revista Crítica de Ciencias Sociais. No.33 Outubro/1991.

RANCIÈRE, Jacques. O desentendimento. São Paulo: Editora 34, 1996.

RANCIÈRE, Jacques. Rancière: 'A política tem sempre uma dimensão estética'. Entrevista concedida à Gabriela Longman e Diego Viana. Revista CULT, 2010. Disponível em https://revistacult.uol.com.br/ home/entrevista-jacques-ranciere/

ROSA, Edelnise Pellegrini. Gênero e habitação: participação e percepção feminina na construção de viveres. 2007. Dissertação (Mestrado) - Programa de Pós-Graduação em Sociologia Política da Universidade Federal de Santa Catarina. Florianópolis, 2007.

SCOTT, Joan. Gênero: uma categoria útil de análise histórica. Educação e Realidade, v. 20, n. 2. p. 7199. 1995.

SILVA, Carmen S. M. Feminismo popular e lutas antissistêmicas. Recife: Edições SOS Corpo. 2016a

SILVA, Carmen S. M. Feminismo popular na amb: uma experiência brasileira. Enfoques. V.15. p. 147163. $2016 \mathrm{~b}$

CUPERTINO, Philipe; GOMES, Carita Chagas; LOPES, Ana Carolina Oliveira. O direito à moradia e o protagonismo das mulheres em ocupações urbanas. Revista do Núcleo de Estudos e Pesquisas em Gênero \& Direito (UFPB) , v. 1, p. 180-198. 2014.

SOARES, Vera. Políticas públicas para igualdade: papel do estado e diretrizes. In GODINHO, Tatau; SILVEIRA, Maria Lúcia da (Org.). Políticas Públicas e Igualdade De Gênero. São Paulo: Prefeitura de São Paulo - Coordenadoria Especial da Mulher, 2004.

SOUZA, Amanda Paulista. As mulheres nos movimentos sociais de moradia - a cidade sob uma perspectiva de gênero. Revista Humanidades em Diálogo. v. 5. p. 93-112 2013.

TAVARES, Rossana Brandão. Indiferença à diferença: espaços urbanos de resistência na perspectiva das desigualdades de gênero. 2015. Tese (Doutorado em Urbanismo) - Programa de PósGraduação em Urbanismo, Universidade Federal do Rio de Janeiro. Rio de Janeiro, 2015.

TAVARES, Rossana Brandão. Práticas sociais de resistência na perspectiva de gênero contra indiferença à diferença: por um planejamento de possibilidades. In XVII ENANPUR - Encontro Nacional da Associação de Pós-Graduação e Pesquisa em Planejamento Urbano e Regional, 2017, São Paulo. Anais [...] São Paulo: FAU/USP, 2017. p. 293-293.

WAISELFISZ, Julio Jacobo. Mapa da Violência 2015: Homicídio de mulheres no Brasil. 2015. Brasilia. Disponível em https://www.mapadaviolencia.org.br/pdf2015/MapaViolencia_2015_mulheres.pdf 